\title{
The impact of conservative soft orthotic intervention with strapping on thoracic kyphotic posture and spinal mobility in children with cerebral palsy: a randomized control trial
}

\author{
Ehab Mohamed Abd El-Kafy* (i) and Shamekh Mohamed El-Shamy
}

\begin{abstract}
Background: This study mainly aimed to evaluate the influences of Thera Togs orthotic undergarment with its strapping system on dorsal kyphotic posture and spinal mobility in children with spastic diplegic cerebral palsy. The study also investigated the impact of the modulation of thoracic kyphosis on balance and risk of falls in these children.

Study design: This study was a randomized control trial.

Participants: Forty children with diplegic cerebral palsy, aged from 8 to 10 years were met the inclusion criteria and participated in this study. Only 38 children completed the study.

Methods: The children in the control group received $2 \mathrm{~h}$ of conventional exercise protocol aiming for modulating thoracic kyphotic posture. The treatment program was conducted 3 times/week, for 12 successive weeks. Children in the study group wore TheraTogs orthoses with the strapping system for $8 \mathrm{~h}$ every day in combination with the conventional exercise program.
\end{abstract}

Outcome measures: For both groups, the primary outcome measures (thoracic kyphotic angle, and thoracic flexion and extension range of motion), and the secondary outcomes (the overall stability index of fall risk test, and the pediatric balance scale score) were recorded at baseline and after completion of the treatment. $T$ test was used to compare the changes within-and between-groups in all measured variables, at baseline and immediately after 12 weeks of treatment.

Results: Children in the study group showed significant improvements in the scores of all primary and secondary measures post-treatment compared to the control group $(P<0.05)$.

Conclusion: Conservative treatment composed of TheraTogs orthotic system with conventional exercise treatment is effective in modulating thoracic kyphosis and improving dorsal range of motion in children with spastic diplegic cerebral palsy. This improvement has a positive influence on postural balance performance and reduces the risk of fall in these children.

Trial registration: The ClinicalTrial.gov PRS (NCT05063175). 30 September 2021—retrospectively registered, https:// clinicaltrials.gov/ct2/show/NCT05063175

Keywords: Cerebral palsy, Kyphosis, TheraTogs, Balance, Risk of fall

*Correspondence: emkafy@uqu.edu.sa

Department of Physical Therapy, Faculty of Applied Medical Sciences,

Umm Al-Qura University, Makkah, Saudi Arabia 


\section{Background}

Kyphosis is a posterior convexity of the spine. It may develop in children with spastic diplegia as a compensatory response to many musculoskeletal problems such as limb and pelvic problems [1]. Kyphosis in children with cerebral palsy is often flexible at a young age, and it has a higher risk of curve progression [2]. It may continue to progress quickly into adulthood and become structured after skeletal maturity. It may need surgical intervention during the adulthood period [3].

The primary target of the therapeutic management of spinal deformity in children with cerebral palsy is to maintain their functional activities to the highest level of quality as much as possible. The management protocols include both conservative and surgical treatments [4]. Conservative treatment includes the prescription of spinal braces and positioning adaptations. A molded thoraco-lumbosacral orthosis can be used for children with movable spinal curvature to delay the progression of the deformity [5].

The strict wearing of a traditional rigid form of spinal braces may result in children's inconvenience, skin irritability, respiratory restriction, feeding problems, and poor functional performance. A soft full-body brace is most appropriate and tolerable by young individuals with movable curves [6].

TheraTogs system which is composed of orthotics undergarment and the strapping system is made from a lightweight, breathable material. It has been made to give a soft and passive body compression to keep a stabilized posture $[7,8]$. TheraTogs strapping system could adjust and control different segments of the neuro-musculoskeletal systems to achieve better biomechanical body alignment and to improve proper posture control $[9,10]$.

Thoracic hyper-kyphosis may negatively influence balance and risk of fall in normal adults [11]. Individuals with cerebral palsy are more susceptible to frequent falls than normal healthy individuals and the impact of that fall is significant. They may have a constant fear of recurring falls, negative body image, and restricted participation in all aspects of life [12, 13].

The available current literature does not adequately evaluate the effects of conservative soft orthoses on the management of kyphosis in children with cerebral palsy. Also, there is a lack in the literature that investigates how the modulation of the sagittal spinal profile, and specifically thoracic kyphosis, affect the postural balance control and the risk of fall in children with cerebral palsy.

Therefore, the purpose of this study was to evaluate the influences of TheraTogs soft orthosis and strapping system on the thoracic kyphotic posture, and dorsal spinal mobility in children with diplegic cerebral palsy. This study also investigated the impact of the modulation of the thoracic kyphosis on balance control and risk of fall in these children.

\section{Methods \\ Design}

The research design of this study was a randomized control trial. It was approved by the Ethics Review Committee of the Faculty of Applied Medical Sciences - Umm Al Qura University. This trial was registered in the ClinicalTr ial.gov PRS (NCT05063175). Children's parents signed consent for permitting the engagement of their children in this study. The study was proceeded according to the Declaration of Helsinki of 1975, as revised in 2013.

The study was conducted in the Department of Physical Therapy - Umm Al Qura University. The involved children were recruited from the kingdom of Saudi Arabia - the western region. The organization responsible for the integrity, conduct, and financial support of this study was the Deanship of Scientific Research at Umm Al Qura University - Grand Code (19-MED-1-01-0005).

\section{Participants}

Children of both sexes with a confirmed diagnosis of spastic diplegic cerebral palsy were selected to participate in this study. These children were between 8 and 10 years old. The degree of spasticity in the affected upper and lower extremity, based on the Modified Ashworth Scale (MAS), ranged between grades $1,1+$, and 2 .

Children were able to comprehend and follow orders. Their gross motor development levels, as measured by Gross Motor Function Classification System (GMFCS), were between levels (I and II), and they had the ability to stand alone for 5 to $10 \mathrm{~min}$ without any assistance. So that, they were able to perform the pre and post-treatment evaluation procedures. The spinal kyphosis, for all participating children, was flexible. The degree of Cobb's angle was not more than $45^{\circ}$. This is because if the degree of kyphosis is above $55^{\circ}$, it is considered as fixed hyperkyphosis; however, kyphosis below this range is flexible and it could be improved by conservative treatment such as exercising or bracing $[14,15]$. Throughout the study period, the participating children were not subjected to any other physical therapy programs except the assigned treatment protocol.

The children were excluded from this study if they had fixed spinal deformities or corrective surgeries interfering with spinal mobility. Children who have a skin allergy to the materials from which the TheraTogs was fabricated have been also excluded. Children who had seizures, perceptual disorders, visual problems, and auditory deficits have not participated as well.

The sample size of this study was calculated based on a preliminary power analysis (power $=0.8, \alpha=0.05$, 
effect size $=0.5$, groups $=2$, and evaluation times $=$ 2). A total sample size of 40 participants was calculated for this study. The participating children were divided equally into two groups. The randomization process was performed by an independent person who was blinded to the study procedures. It was performed simply by adding a specific identification number for each participating child. SPSS program was used to randomly assign children to both groups.

\section{Assessment}

Assessments of the children with diplegic cerebral palsy were conducted by evaluators who did not participate in the application of intervention and were also blinded from the randomization process. The evaluation was carried out to measure the changes in the mean scores of the following primary and secondary outcome measures from pre to post-treatment; primary outcome measures included (1) the thoracic kyphosis angle $\left(^{\circ}\right.$ ) and (2) thoracic flexion and extension range of motion (degree), while the secondary outcome measures included (3) the overall stability index of the fall risk test (\%) and (4) the Pediatric Balance Scale score.

DIERS Formetric 3D/4D spine and posture analysis system. It is a light-optical scanning technique that depends on video-raster-stereography (VRS). It is a special device for contactless, quick, and radiation-free dynamic and static evaluation of the spine. The DIERS formetric supplies a comprehensive report about the statics and the posture of the entire spine in only one evaluating process. In this study, it was used for measuring the sagittal geometry of the back surface of the participating children according to a contactless 3D scan.

Formetric 3D/4D spine and posture analysis system is valid and reliable equipment for measuring lateral and frontal spinal curves, the rotation of vertebrae, and the pelvic deviations [16]. Thoracic kyphotic angle for each child was calculated from the sagittal profile by formetric system: Kyphotic angle measured between vertebral prominence (VP) and the estimated location of the 12th thoracic vertebra (T12).

Spinal mouse, a computerized spinal assessment device, was used for measuring the spinal flexion and extension range of motion (ROM) in a non-invasive way. It is a reliable and valid device for evaluating spinal intersegmental mobility [17]. Measurements were recorded while the children stood bare-back and the evaluator moved the spinal mouse along their spinal columns from 7 th cervical vertebra to the rima ani (3rd sacral vertebra). The evaluation was performed from the following three successive spinal positions: (1) upright erect, (2) maximal flexion, and (3) maximal extension.
Biodex Balance System SD (BBS; Biodex Inc., Shirley, $\mathrm{NY)}$ was utilized as a reliable and valid device for measuring the stability indices of the Risk of Fall test from standing position at dynamic mode (12) of platform tilt [18]. The Biodex system has a static mode and 12 levels of dynamic platform tilt \{level (12) with greatest stability, while level (1) with the least stability\}.

The dynamic level 12 was selected, in this study, for conducting the fall risk test. The recorded result for every participant was automatically saved and was compared to the normative values stored in the equipment according to their age. The closer the score that was recorded to the typical score, stored in the equipment software, the lower the risk of fall. On the contrary, the higher the score than that stored, the greater the risk of fall which indicated poor balance performance.

The Pediatric Balance Scale (PBS) is a valid and reliable test to assess and re-assess balance deficits in children with mild and moderate motor disabilities. The test includes fourteen tasks that evaluate balance abilities and motor performance in children. The rating score for each item is ranged from 0 to 4 , where 0 is the lowest score and 56 is the highest possible score for all tasks that indicates the best balance and motor performance [19].

\section{Interventions}

Both groups (control and study) received the conventional physical therapy protocol aiming for modulating thoracic kyphotic posture and improving the axial postural alignment. The conventional exercise protocol for both groups is fully outlined in Additional file 1: Appendix 1.

The conventional therapeutic protocol for every child was 3 sessions/week for 12 consecutive weeks. It was applied by two qualified physical therapists. Every treatment session was conducted for $2 \mathrm{~h}$ with a 15-min rest between the two training hours. Materials used in the application of conventional physical therapy treatment included therapeutic mats, balls, wedges, rolls, parallel bars, treadmills, steppers, balance boards, and Bobath beds.

The children in the study group received the conventional protocol given to the control group. Moreover, they wore TheraTogs orthotic undergarment with the strapping system $8 \mathrm{~h}$ every day for the 12 consecutive weeks. For every participating child, TheraTogs was applied after appropriate and accurate pre-treatment evaluation. Application and fitting of TheraTogs and strapping protocol was applied by a qualified physical therapist who was certified on TheraTogs fitting.

A TheraTogs orthotic undergarment developed by Cusick [20] is composed of a sleeveless Tank-Top (vest), two shorts (Hipster) each with two thigh and limb cuffs. 
They are designed to be worn directly on the skin as undergarments that allow unobstructed toileting. A wellfitted TheraTogs system provides the wearer a vertical compression and stiffness to support posture, and reinforce stability.

Each child had his/her own TheraTogs orthotic undergarment. It was not allowed for any child to share his/ her orthosis with others for two reasons: (1) to avoid any infectious disease transfer and (2) every child had its special size, which might not fit with others. In this study, the participating children wore the TheraTogs and strapping system under their regular dresses, so it was not annoying or disturbing.

A preparatory course for (14 days) before starting the treatment program was given to all participating children to become accustomed to wearing the TheraTogs orthotic undergarment and strapping system. The wearing period gradually increased from $1 \mathrm{~h}$ at the beginning of the course until reached the $8 \mathrm{~h}$ that were planned in this study.

Throughout this course, the therapist who is responsible for the TheraTogs protocol trained one of the child's family members on (1) how to fit the TheraTogs orthosis to his/her child, and (2) how to apply the prescribed strapping technique for the involved body parts. By the end of this course, the therapist made sure of the skills of this member in the application of the TheraTogs protocol before the actual beginning of the treatment program.

It was not allowed to start the treatment program with TheraTogs until making sure of the family member's skill and proficiency in providing the prescribed TheraTogs protocol. Any member who was not successful in this preparatory course was retrained again. The therapist daily followed up the process of wearing TheraTogs and strapping by telephone with this member and made sure that the process was completed successfully. This daily communication continued throughout the treatment period (12 weeks).

The fitting and strapping techniques of TheraTogs system for all participating children in the study group are fully outlined in Additional file 2: Appendix 2.

\section{Statistical analysis}

The statistical analysis for all recorded scores pre- and post-treatment was reported as mean \pm standard deviation (SD). The Shapiro-Wilk test and the Levine's test were used to test the variables' normal distribution and variances homogeneity, respectively. The data of this study were homogeneous and normally distributed. Paired $t$ test was used to compare the changes within both groups, pre-and immediately post-treatment. While the comparison between both groups was carried out by using unpaired $t$ test. Recorded data were analyzed by using SPSS computer program version 25.00. $P$ values less than 0.05 were accepted to represent a statistical significance.

\section{Results}

A total of 67 children with spastic diplegic cerebral palsy were selected to join in this study. Forty of them met the inclusion criteria and participated in different study processes. The study flow chart is illustrated in Fig. 1. The baseline demographic characteristics of the participants are outlined in Table 1.

Table 2 showed that there were no significant differences between both groups pre-treatment when comparing the mean values of thoracic kyphosis $\left(^{\circ}\right)$, thoracic flexion and extension range of motion (degree), the overall stability indices (\%) of the fall risk test , and the total score of the pediatric balance scale. On the other hand, post-treatment data comparison demonstrated significant differences in favor of the study group $(P<0.05)$.

Table 2 also illustrated that there were significant differences within both groups between baseline and immediately post-treatment values in all measured parameters.

\section{Discussion}

The findings of this study showed significant differences, in all measured variables, post-treatment in favor of the study group than the control group. These findings reflected the effectiveness of TheraTogs soft orthotic undergarment and the strapping system in combination with the conventional exercise treatment on modulating kyphotic posture and increasing the thoracic spinal mobility. This modulation of kyphotic posture was reflected in the improvement of postural balance control and reducing the risk of falls in the participated children.

Regarding the study group, the better reduction of kyphotic angle and the improvement of thoracic spinal mobility could be attributed to the application of TheraTogs orthosis and strapping system. Wearing TheraTogs orthotic undergarment provided children included, in the study group, with a comfortable sense of compression with vertical stiffness to their upper body trunk, and pelvis. This effect helped them in assuming proper vertical postural alignment and reinforcing their core stability. Previous studies showed that the TheraTogs system could adjust and modulate different elements of the musculoskeletal systems to assume proper biomechanical alignments of body posture. It is also helpful in augmenting trunk stiffness, reinforcing proximal stability, facilitating spatial orientation of different body segments, and consequently, improving postural control [7, 21].

Additionally, TheraTogs strapping system provided a continuous external backward vertical tension that might 


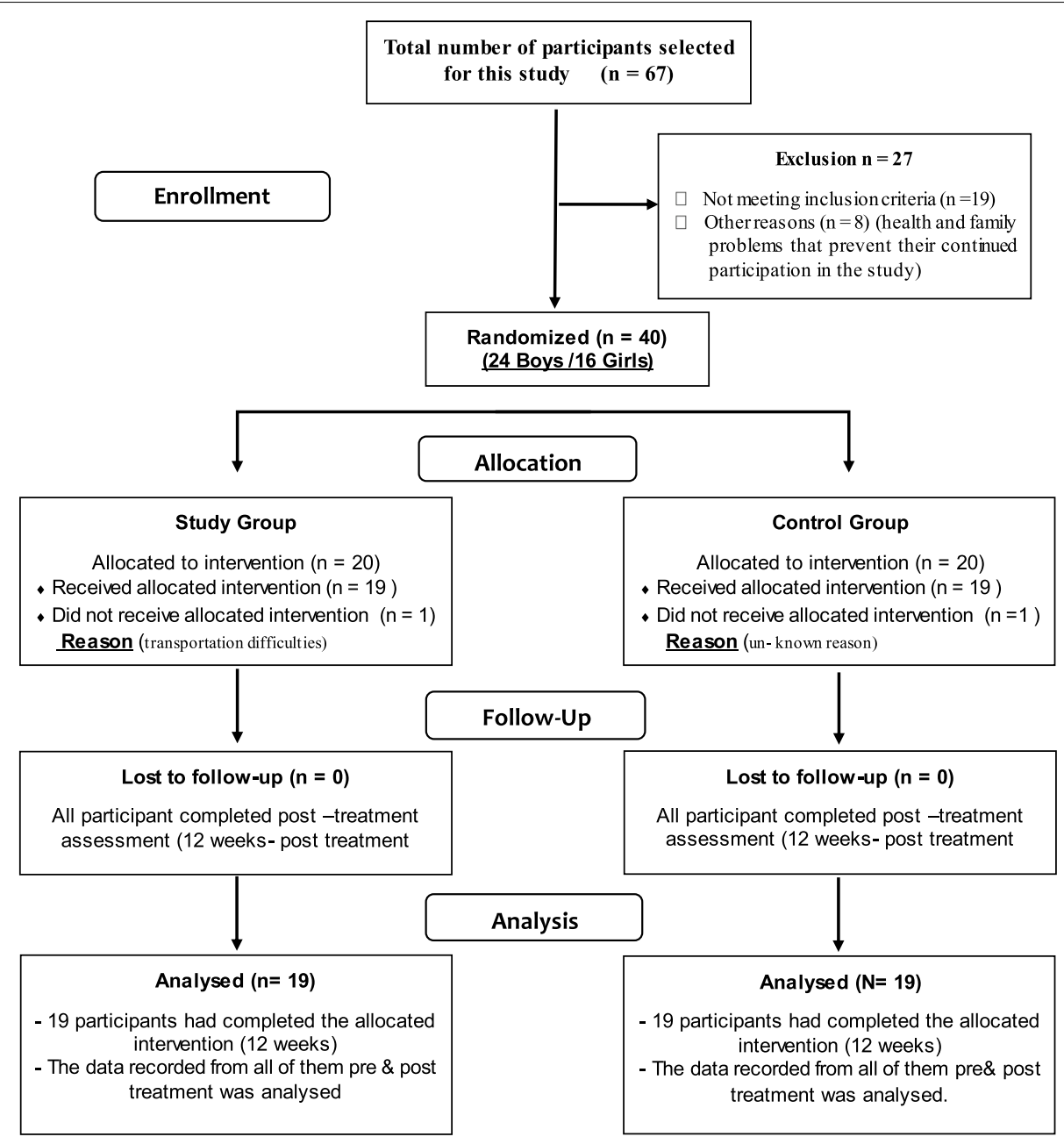

Fig. 1 Flow diagram of the study

Table 1 The demographic characteristics of the participants

\begin{tabular}{llll}
\hline Demographics characteristics & $\begin{array}{l}\text { Control group } \\
\text { (20) children }\end{array}$ & $\begin{array}{l}\text { Study group } \\
\text { (20) children }\end{array}$ \\
\hline $\begin{array}{llll}\text { Age (years) (mean } \pm \text { SD) } \\
\text { Sex }\end{array}$ & $9.41 \pm 0.45$ & $9.28 \pm 0.37$ \\
& Boys & 11 & 13 \\
& Girls & 9 & 7 \\
Height (cm) (mean \pm SD) & & $141 \pm 8.25$ & $140 \pm 7.35$ \\
Spasticity grades (MAS) & UL: 1 & 7 & 5 \\
& LL: $1+$ & & \\
& UL: 1 & 6 & 9 \\
& LL: 2 & & \\
& UL: $1+$ & 7 & 6 \\
& LL: 2 & & 8 \\
GMFCS level & I & 5 & 12 \\
\hline
\end{tabular}

SD standard deviation, UL upper limb, LL lower limb, MAS Modified Ashworth Scale, GMFCS Gross Motor Function Classification System enhance the stretching of tight soft tissues and muscles of the ventral aspect of the thoracic spine and facilitate the actions of the weak dorsal spinal muscles resulting from the presence of kyphosis. Some studies reported that TheraTogs and the strapping system could restore the desirable length of the weak muscle and provide the additional tension that facilitates the recruitment of more motor units to produce more tension and improve muscle strength [21-23].

This double effect which is, stretching the tight soft tissues and reinforcement of the action of weak muscles could promote the reduction of the thoracic kyphotic curve, and minimize the progression of the thoracic kyphotic angle. The modulation of the thoracic kyphotic curve provided the opportunity for improving the thoracic flexion and extension range of motion.

Several studies have proved the effectiveness of conservative spinal orthoses on the modulation of the sagittal spinal curvature in flexible cases of kyphosis. They 
Table 2 Within- and between-group differences for all measured variables, at baseline and immediately after 12 weeks of treatment

\begin{tabular}{|c|c|c|c|c|}
\hline \multirow[t]{2}{*}{ Variables } & \multirow[t]{2}{*}{ Evaluation time } & \multicolumn{2}{|l|}{ Mean \pm SD } & \multirow[t]{2}{*}{$P$ value } \\
\hline & & Study group & Control group & \\
\hline \multirow[t]{3}{*}{ Thoracic kyphotic angle $\left(^{\circ}\right)$} & Pre-treatment & $37.53 \pm 4.32$ & $36.75 \pm 3.94$ & $0.654^{b}$ \\
\hline & Post-treatment & $28.41 \pm 6.13$ & $33.22 \pm 5.45$ & $0.002^{\mathrm{a}}$ \\
\hline & $P$ value & $0.001^{\mathrm{a}}$ & $0.027^{\mathrm{a}}$ & \\
\hline \multirow[t]{3}{*}{ Thoracic flexion range of motion (degree) } & Pre-treatment & $36.25 \pm 1.83$ & $37.39 \pm 2.04$ & $0.782^{b}$ \\
\hline & Post-treatment & $49.54 \pm 2.62$ & $43.38 \pm 2.85$ & $0.013^{\mathrm{a}}$ \\
\hline & $P$ value & $0.001^{\mathrm{a}}$ & $0.012^{\mathrm{a}}$ & \\
\hline \multirow[t]{3}{*}{ Thoracic extension range of motion (degree) } & Pre-treatment & $32.48 \pm 2.19$ & $33.63 \pm 2.41$ & $0.471^{b}$ \\
\hline & Post-treatment & $44.51 \pm 1.57$ & $39.42 \pm 1.86$ & $0.011^{\mathrm{a}}$ \\
\hline & $P$ value & $0.001^{\mathrm{a}}$ & $0.007^{\mathrm{a}}$ & \\
\hline \multirow[t]{3}{*}{ Overall stability index of the fall risk test (\%) } & Pre-treatment & $12.62 \pm 0.47$ & $12.28 \pm 0.35$ & $0.835^{b}$ \\
\hline & Post-treatment & $9.41 \pm 0.53$ & $11.171 \pm 0.46$ & $0.001^{\mathrm{a}}$ \\
\hline & $P$ value & $0.001^{\mathrm{a}}$ & $0.018^{a}$ & \\
\hline \multirow[t]{3}{*}{ Pediatric balance scale score } & Pre-treatment & $22.91 \pm 0.36$ & $23.27 \pm 0.25$ & $0.746^{b}$ \\
\hline & Post-treatment & $37.52 \pm 0.41$ & $30.48 \pm 0.47$ & $0.001^{\mathrm{a}}$ \\
\hline & $P$ value & $0.001^{\mathrm{a}}$ & $0.001^{\mathrm{a}}$ & \\
\hline
\end{tabular}

SD standard deviation

a Significant difference between both groups $(P<0.05)$

${ }^{\mathrm{b}}$ Non-significant difference between both groups $(P<0.05)$

found that the correction of the kyphotic deviation was maintained as long as the braces or orthoses were used [24-26]. Another study recommended that TheraTogs orthotic undergarment and its strapping system might be a beneficial intervention for improving spinal sagittal geometry in children with diplegic cerebral palsy [27]. Many other studies have pointed out that bracing and orthoses, as a conservative treatment for different spinal deformities in different planes, were effective if they have been worn for many hours per day. They emphasized that the longer the wearing hours, the better the effect [28, 29].

There is a negative relationship between the presence of kyphosis with balance performance. Children with increased kyphotic posture have an anterior shift of the head, prominence of the scapula, and consequently, the line of gravity abnormally projects anteriorly [30]. This forward shifting of the line of gravity adversely affects postural balance control and decreases the stability limits in all directions $[31,32]$. Moreover, children with thoracic hyper-kyphotic posture are frequently associated with an increased risk of falls [33, 34].

Many studies proved that TheraTogs orthoses and the strapping system are efficient in improving balance control, walking abilities, and gait parameters in children with cerebral palsy $[7,9,10,35-37]$. The reduction of the thoracic kyphotic posture obtained in children of both groups, specifically in the study group, led to the minimization of the abnormal forward shifting of the line of gravity. The re-adjustment of the line of gravity would have a positive reflection on improving the children's balance control, minimizing the risk of falls, and lowering the rate of their frequent falls.

The results of this study concluded that the application of the TheraTogs orthotic undergarment and strapping system, for at least $8 \mathrm{~h}$ daily, in combination with the conventional exercise protocol could be an effective conservative treatment for the cases of flexible thoracic kyphosis in children with spastic diplegic cerebral palsy.

This study has some limitations that need to be considered: (1) given the nature of the therapeutic interventions in this study, it was not possible for the treating therapists and the children in this study to be blinded, (2) the level of tension of the elastic strapping elements was not accurately measured, (3) large sample of children are needed to make a generalization for the results of this study, and (4) the children in the study group need follow up posttraining to be certain from the long-lasting benefits of the TheraTogs on thoracic kyphosis.

Future work will be needed to investigate the effects of other treatment periods of wearing TheraTogs and external strapping to determine the most appropriate dose-response of this intervention. Further studies are also recommended to examine the effectiveness of this orthotic intervention on correcting other types of spinal malalignments in different types of cerebral palsy. 


\section{Supplementary Information}

The online version contains supplementary material available at https://doi. org/10.1186/s43161-021-00068-2.

Additional file 1: Appendix 1. The Conventional Exercise Protocol.

Additional file 2: Appendix 2. TheraTogs fitting and strapping technique.

\section{Acknowledgements}

The authors would like to thank the Deanship of Scientific Research at Umm Al Qura University, KKingdom of Saudi Arabia for supporting this work by grand code (19-MED-1-01-0005). The lauthors also express their deepest appreciation and thanks to all children who participated in this study and their parents. Their valuable contributions were crucial to accomplish this study.

\section{Authors' contributions}

All authors conceived and designed the study, conducted the data collection, analyzed and interpreted the data in addition to reviewing the final results, are responsible for the findings, and have critically reviewed and approved the final draft of the article. The authors read and approved the final manuscript.

\section{Funding}

This research was funded.

\section{Availability of data and materials}

The datasets generated during and/or analyzed during the current study are available from the corresponding author on reasonable request.

\section{Declarations}

Ethics approval and consent to participate

The study was approved by the Ethical Committee of the Faculty of Applied Medical Sciences, Umm Al Qura University. Parents of all participants signed written informed consents before starting the study.

\section{Competing interests}

The authors declare that they have no competing interests.

Received: 18 November 2021 Accepted: 19 December 2021 Published online: 02 March 2022

\section{References}

1. Suh SW, Suh DH, Kim JW, Park JH, Hong JY. Analysis of sagittal spinopelvic parameters in cerebral palsy .Clinical study. Spine. 2013;13(8):882-8. https://doi.org/10.1016/j.spinee.2013.02.011.

2. Lee SY, Chung CY, Lee KM, Kwon SS, Cho KJ, Park MS. Annual changes in radiographic indices of the spine in cerebral palsy patients. Eur Spine J. 2016;25(3):679-86. https://doi.org/10.1007/s00586-014-3746-4

3. Umnov W. Kyphosis in patients with cerebral palsy: causes of its development and correctional possibilities (literature review). Pediatric Traumatol Orthop Reconstr Surg. 2015;3:48-51. https://doi.org/10.17816/PTORS 3348-51.

4. Pountney T. Cerebral Palsy. In: Pountney T, editor. Physical therapy for children. USA: Butterworth Heinemann Elsevier; 2007. p. 90-108.

5. Terjesen $\mathrm{T}$, Lange JE, Steen $\mathrm{H}$. Treatment of scoliosis with spinal bracing in quadriplegic cerebral palsy. Dev Med Child Neurol. 2000;42(7):448-54. https://doi.org/10.1017/s0012162200000840

6. Tsirikos Al. Development and treatment of spinal deformity in patients with cerebral palsy. Indian J Orthop. 2010;44(2):148-58. https://doi.org/ 10.4103/0019-5413.62052

7. Flanagan A, Krzak J, Peer M, Johnson P, Urban M. Evaluation of short-term intensive orthotic garment use in children who have cerebral palsy. Pediatr Phys| Ther. 2009:21(2):201-4. https://doi.org/10.1097/PEP.0b013e3181 a347ab.

8. Almeida KM, Fonseca ST, Figueiredo PRP, Aquino A, Mancini MC. Effects of interventions with therapeutic suits (clothing) on impairments and functional limitations of children with cerebral palsy: a systematic review. Braz J Phys Ther. 2017;21(5):307-20. https://doi.org/10.1016/j.bjpt.2017. 06.009 .

9. Abd El-Kafy EM. The clinical impact of orthotic correction of lower limb rotational deformities in children with cerebral palsy: a randomized controlled trial. Clin Rehabil. 2014;28(10):1004-14. https://doi.org/10.1177/ 0269215514533710.

10. Ehlert R, Manfio EF, Heidrich RDO, Goldani R. Cerebral palsy: Influence of TheraTogs ${ }^{\circledR}$ on gait, posture and in functional performance. Fisioter Mov. 2017;30(2):307-17. https://doi.org/10.1590/1980-5918.030.002.AO11.

11. Fernandes VLS, Ribeiro DM, Fernandes LC, de Menezes RL. Postural changes versus balance control and falls in community-living older adults: a systematic review. Fisioter. Mov. 2018;31:e003125. https://doi. org/10.1590/1980-5918.031.AO25

12. Morgan P, McDonald R, McGinley J. Perceived cause. environmental factors, and consequences of fall in adults with cerebral palsy: a preliminary mixed methods study. Rehabil Res Pract. 2015;1:19639. https://doi.org/10. $1155 / 2015 / 196395$.

13. Ryan JM, Cameron MH, Liverani S, Smith KJ, O'connell N, Peterson MD, et al. Incidence of falls among adults with cerebral palsy: a cohort study using primary care data. Dev Med Child Neurol. 2020;62(4):477482. https://doi.org/10.1111/dmcn.14444.

14. Cho WJ, Kang CN, Park YS, Kim HJ, Jl C. Surgical correction of fixed kyphosis. Asian Spine Journal. 2007;1(1):12-8. https://doi.org/10.4184/asj. 2007.1.1.12.

15. Staheli LT. Fundamentals of Pediatric Orthopedics. 4th ed. Philadelphia: LWW; 2007

16. Degenhardt BF, Staeks Z, Bhatia S. Reliability of the DIERS Formetric 4D spine shape parameters in adults without postural deformities. Biomed Res Int. 2020;13:1796247. https://doi.org/10.1155/2020/1796247.

17. Livanelioglu A, Kaya F, Nabiyev V, Demirkiran G, Firat T. The validity and reliability of "Spinal Mouse" assessment of spinal curvatures in the frontal plane in pediatric adolescent idiopathic thoraco-lumbar curves. Eur Spine J. 2016;25(2):476-82. https://doi.org/10.1007/s00586-015-3945-7.

18. Cachupe WJC, Shifflett B, Kahanov L, Wughalter EH. Reliability of Biodex Balance System measures. Meas Phys Educ Exerc Sci. 2001;5(2):97-108. https://doi.org/10.1207/S15327841MPEE0502_3.

19. Franjoine MR, Gunther JS, Taylor MJ. Pediatric balance scale: a modified version of the berg balance scale for the school- age child with mild to moderate motor impairment. Pediatr Phys Ther. 2003;15(2):114-28. https://doi.org/10.1097/01.PEP.0000068117.48023.18.

20. Cusick B. TheraTogs TM, http://www.theratogs.com (accessed 2007)

21. Romeo DM, Specchia A, Sini F, Bompard S, Di Polito A, Del Vecchio A, et al Effects of Lycra suits in children with cerebral palsy. Eur J Paediatr Neurol. 2018;22(5):831-6. https://doi.org/10.1016/j.ejpn.2018.04.014.

22. Faltermeier K, Reiter M, Hasse A, Wimmer C, Rosner V, Berweck S. Possible applications for TheraTogs in pediatric neurorehabilitation. Neuropediatrics. 2014;45(S01):20. https://doi.org/10.1055/s-0034-1390592.

23. El Fiky A, Elsodany A, Abd E-KE. Effect of TheraTogs orthotic undergarment on postural balance control, risk of fall, and walking abilities in Saudi individuals with chronic stroke. Jokull J. 2016:66(5):23-35.

24. Yaman O, Dalbayrak S. Kyphosis and review of the literature. Turk Neurosurg. 2014;24(4):455-65. https://doi.org/10.5137/1019-5149.JTN. 8940-13.0.

25. Abrisham SMJ, Ardekani MRS, Mzarch MAB. Evaluation of the normal range of thoracic kyphosis and lumbar lordosis angles using EOS imaging. Maedica (Bucur). 2020;15(1):87-91. https://doi.org/10.26574/maedi ca.2020.15.1.87.

26. Sheehan DD, Grayhack J. Pediatric scoliosis and kyphosis: an overview of diagnosis, management, and surgical treatment. Pediatr Ann. 2017;46(12):e472-80. https://doi.org/10.3928/19382359-20171113-01.

27. Abd EM, Kafy E, El-Shamy SM. Efficacy of TheraTogs orthotic undergarment on modulation of spinal geometry in children with diplegic cerebral palsy. Bull Facult Physical Ther. 2021:26:29. https://doi.org/10.1186/ s43161-021-00047-7.

28. Negrini S, Minozzi S, Bettany-Saltikov J, Chockalingam N, Grivas TB, Kotwicki T, et al. Braces for idiopathic scoliosis in adolescents. Cochrane Data-base Syst Rev. 2015;6:CD006850. https://doi.org/10.1002/14651858. CD006850.pub3. 
29. Karol LA, Virostek D, Felton K, Jo CH, Butler L. The effect of the Risser stage on bracing outcome in adolescent idiopathic scoliosis. J Bone Joint Surg. 2016;98(15):1253-9. https://doi.org/10.2106/JBJS.15.01313.

30. Sinaki M, Brey RH, Hughes CA, Larson DR, Kaufman KR. Balance disorder and increased risk of falls in osteoporosis and kyphosis: significance of kyphotic posture and muscle strength. Osteoporos Int. 2005;16(8):100410. https://doi.org/10.1007/s00198-004-1791-2.

31. Abe Y, Aoyagi K, Tsurumoto T, Chen CY, Kanagae M, Mizukami S, et al. Association of spinal inclination with physical performance measures among community-dwelling Japanese women aged 40 years and older. Geriatr Gerontol Int. 2013;13(4):881-6. https://doi.org/10.1111/ggi.12020.

32. Groot MH, van der Jagt-Willems HC, van Campen JP, Lems WF, Lamoth CJ. Testing postural control among various osteoporotic patient groups: a literature review. Geriatr Gerontol Int. 2012;12(4):573-85. https://doi.org/ 10.1111/j.1447-0594.2012.00856.x.

33. Eum R, Leveille SG, Kiely DK, Kiel DP, Samelson EJ, Bean JF. Is kyphosis related to mobility, balance, and disability? Am J Phys Med Rehabil. 2013:92(11):980-9. https://doi.org/10.1097/PHM.0b013e31829233ee.

34. Katzman WB, Harrison SL, Fink HA, Marshall LM, Orwoll E, Barrett-Connor E, et al. Physical function in older men with hyperkyphosis. J Gerontol A Biol Sci Med Sci. 2015;5:635-40. https://doi.org/10.1093/gerona/glu213.

35. Abd El Kafy EM, El-Shemy SA. Modulation of lower extremity rotational deformities using TheraTogs ${ }^{\mathrm{TM}}$ and strapping system in children with spastic diplegia. Egypt J Neurol Psychiat Neurosurg. 2013;50(4):397-402.

36. Angelakos I, Mills C, O'Halloran J. The effects of compression garments on stability and lower limb kinematics during a forward lunge. J Hum Kinet. 2020;71(1):59-68. https://doi.org/10.2478/hukin-2019-0074.

37. Jung $\mathrm{JH}$, Cho H, Lee GC. Immediate effects of orthotic garment and strapping system on balance and gait in children with spastic diplegia. Neurol Asia. 2021;26(2):355-60.

\section{Publisher's Note}

Springer Nature remains neutral with regard to jurisdictional claims in pub-

lished maps and institutional affiliations.

\section{Submit your manuscript to a SpringerOpen ${ }^{\circ}$ journal and benefit from:}

- Convenient online submission

- Rigorous peer review

- Open access: articles freely available online

- High visibility within the field

- Retaining the copyright to your article

Submit your next manuscript at $\boldsymbol{\nabla}$ springeropen.com 